\title{
NMR Spectral Studies of some Six-membered and Seven-membered Saturated Hetero Cyclic Compounds: Calculation of Torsional Angles from Vicinal Coupling Constants - using Altona's Equation and its Comparison with DAERM Method
}

\author{
S. Rosy Christy* and G. Mathubala \\ Department of Chemistry, Bharath University, Selaiyur, Chennai - 600 073, India; \\ rosyma28@yahoo.com,madhu2705@gmail.com
}

\begin{abstract}
Some six and seven membered saturated hetero cyclic compounds were prepared; from their vicinal coupling constants, proton - proton Torsional angles were calculated using Altona's Equation. ${ }^{1} \mathrm{H}$ NMR spectra were recorded in DMSO - $\mathrm{d}_{6}$. The chemical shifts were compared with those in $\mathrm{CDCl}_{3}$. The COSY, NOESY and ${ }^{13} \mathrm{C}-{ }^{1} \mathrm{H}$ correlation spectra had been recorded to assign the signals unambiguously. Thereafter, torsional angles were calculated using electronegativity values of the substituents; the electronegativity value of oxygen was taken to be 3.50. Calculations were made accurately.
\end{abstract}

Keywords: Altona's Equation, COSY, NOESY, Orientatin, Conformation

\section{Intoduction}

Ever since Barton pointed out the importance of conformational analysis, there has been a rapid development in the conformational analysis of various systems. Nuclear magnetic resonance spectroscopy is a powerful tool for such analysis. ${ }^{1} \mathrm{H},{ }^{13} \mathrm{C},{ }^{15} \mathrm{~N},{ }^{17} \mathrm{O}$ and ${ }^{33} \mathrm{~S}$ are the nuclei used for analysis ${ }^{1}$. Nowadays 2-D -NMR spectroscopy is also used for structural diagnosis.

\section{$1.1{ }^{1} \mathrm{H}$ NMR Spectroscopy}

The important measurables in the ${ }^{1} \mathrm{H}$ NMR spectra are Chemical Shifts and Constants.

\section{$1.2{ }^{1} \mathrm{H}$ Chemical Shift}

Chemical shift of a proton is affected by the electron density around it; the higher the electron density, the higher the field of absorption. The chemical shift $\mathrm{s}$ for $\mathrm{CH}_{3} \mathrm{I}$, $\mathrm{CH}_{3} \mathrm{Br}, \mathrm{CH}_{3} \mathrm{Cl}$, and $\mathrm{CH}_{3} \mathrm{~F}$ are 2.16, 2.68, 3.05 and 4.26 ppm respectively. The values are in line with the inductive effects of the halogen atoms.

Diamagnetic anisotropy arises due to ring currents and affects the chemical shift. This can cause either shielding or deshielding of a proton. All the ring protons of acetophenone are found downfield because of the ring current effect. The ortho protons are shifted slightly further downfield because of the additional de -shielding effect of the carbonyl group.

In [18]-annulene [1], the protons outside the ring are strongly de-shielded [ $2.3 \mathrm{ppm}]$ and the protons inside are strongly shielded $[\delta-3.0 \mathrm{ppm}]$.

The anisotropic effects of the $\sigma$ - electrons of $\mathrm{C}-\mathrm{C}$ bond are small as compared to the circulating $\pi$ electrons. The equatorial protons in cyclohexane resonate at $0.5 \mathrm{ppm}$ higher than the $\sigma$ - electrons in the $\mathrm{C}_{\beta}-\mathrm{C}_{\gamma}$ bonds

The chemical shift also depends on the environment. For example, E and Z Stibenes differ in the chemical shifts of the olefinic protons. In E-Stilbenes [2], these protons 
appear at $6.99 \mathrm{ppm}$, where as in Z-Stibene [3] these protons appear at $6.49 \mathrm{ppm}$.

Bhacca and Williams ${ }^{2}$ have noted the effect of a number of substituents like $\mathrm{OH}, \mathrm{Oac}$, and $\mathrm{SH}$ on the chemical shifts of ring protons. The introduction of a vicinal axial substituent causes the resonance of an equatorial proton to move upfield by $0.1-0.3 \mathrm{ppm}$ (Type A) and the resonance of an axial proton to move downfield by about $0 . p p m$ (Type B). The introduction of a vicinal equatorial proton to move upfield by about $0.3 \mathrm{ppm}$ (Types $\mathrm{C}$ and $\mathrm{D}$ ). Further, a large variety of substituents cause pronounced downfield shifts (0.3-0.5 ppm) when in 1, 3 - diaxial configuration (Type $\mathrm{E}$ ) with respect to protons.

Booth, from the chemical shift values of substituted cyclohexanols, has found that the methyl group also exerts similar influence on the chemical shifts of ring protons. For example, the effect of an equatorial methyl group on the resonance of an axial proton on the adjacent carbon has been calculated to be about $0.4 \mathrm{ppm}$ by comparing the chemical shifts of carbinol protons of Trans 2 - Methylcyclohexanes [4] and Trans 4 - t-butylcyclohexanol [5].

Thus, it is seen that the effect of a substituent on the chemical shift of ring protons depends on its configuration. Hence, the influence of a substituent on the chemical shifts of ring protons can be used for configuration assignments.

\section{Proton - Proton Coupling Constants}

Coupling constants are of immense use in configurational and conformational studies. Vicinal coupling constant between two protons depends on their relative positions. For example, in 1,2 - disubstituted ethenes, the vicinal coupling constant between the olefinic protons is always larger for trans isomer than for cis isomer 13.

In a saturated system, the vicinal coupling constants depend on the dihedral angle between them. Karplus31 gave equations 1 and 2 relating the coupling constants with the dihedral angles.

${ }^{1} \mathrm{H}$ NMR spectra have been recorded for $\mathrm{N}$ - methyl t [3]-isopropyl - r - [2], c[6]- diphenylpiperidin-4-one [16] and its oxime [17] at $400 \mathrm{MHZ}^{3}$. Analysis of the vicinal coupling constants have suggested that boat from 18 contributes to these compounds.
Coupling constants have also been used for studying conformational equlibria. Abraham and Griffiths ${ }^{54}$ have studied the conformational equlibria in 2 - chlorocyclohexanone [19] in various solvents. The percentage of the equatorial conformer in $\mathrm{CCl}_{4}$ has been found to be 31.6. It has been found that the percentage of the equatorial conformation increases with increase in solvent polarity.

The conformational equilibrium of 1 - methyl 1 - phenylcyclohexane has been studied by Eliel and Manoharan. Conformers 20a and 20b have been found to be present in quite unequal amounts.

\section{3. ${ }^{13} \mathrm{C}$ NMR Spectroscopy}

\section{$3.1{ }^{13} \mathrm{C}$ Chemical Shift}

${ }^{13} \mathrm{C}$ chemical shift depends on many factors. Lambert et al.have studied the effect of heteroatom in monoheteracyclohexanes 26 on the shifts of ring carbons. The $\alpha$ - shift is a steep function of the electronegativity of the heteroatom X. An increase by one unit in electronegativity produces a downfield shift of about $50 \mathrm{ppm}$. However, the effect of hetero atom electronegativity on $\beta$ and $\gamma$ carbons is small.

The effect of introduction of heteroatom in 27 was studied by Berlin et al. The deshielding effect of heteroatom on the benzylic carbon decreases in the order $\mathrm{O}>$ $\mathrm{NMe}>\mathrm{NH}>\mathrm{S}$. The heteroatom causes an upfield shift in the carbonyl resonance, and this upfield shift has been attributed to a field effect.

All $\gamma$ - anti substituents cause increased shielding on C- 5 and this has been attributed to the presence of $\alpha$ and $\gamma$ protons. The $\alpha \gamma$ - anti effect C-3 is found to be rather deshielding.

The $\gamma$ - gauch effect, arising from the steric compression caused by 1, 3 - syn - diaxial interaction, has been widely used to determine the configuration of six - membered ring compounds. Thus, the $\beta$ - isomer of 1, 3 - dimethyl - 4 - phenylpiperidine has been assigned the cis configuration 33 with an axial orientation of the methyl group at C-3, based on the observation that C- 5 resonates upfield $(24.8 \mathrm{ppm})$ compared with that in 1-methyl - 4 - phenylpiperidine (32.9 ppm).

Jones et al. have assigned an axial oriental for the phenyl group in the $\alpha$ - isomer of 4 - hydroxyl - 1,2 - dimethyl - 4 - phenylpiperidine [34a], based on the upfield shift of the ipso carbon (by 3-8 ppm) compared with that in the $\beta$ - isomer [34b] where the phenyl group is equatorial. 
Table 1. Coupling constants

\begin{tabular}{ll}
\hline \multicolumn{1}{c}{ Compound } & ${ }^{1} \mathrm{~J}_{\mathrm{CH}[\mathrm{Hz}]}$ \\
\hline Methane & 125.0 \\
Ethane & 124.9 \\
Propane & 114.2 \\
Chloromethane & 150.0 \\
Methanol & 141.0 \\
Benzene & 165.0 \\
\hline
\end{tabular}

Jones and co - workers have assigned the configurations of methyl and phenyl groups in various isomeric 1,2,5 - trimethyl - 4 - phenylpiperidines, 4 - hydroxyl - 1,2,5 - trimethyl - 4 - phenylpiperidines ${ }^{4}$ and 4 - hydroxyl 1,3,5 - trimethyl - 4 - phenylpiperidines, using ${ }^{13} \mathrm{C}$ chemical shifts.

From a study of various di-and tri - methylcyclohexanes, Grant and dalling ${ }^{5}$ have found that an axial methyl group shifts the resonance of C-2, C-3 and C- 4 by 1.40, 5.41 and $-6.37 \mathrm{ppm}$, whereas for an equatorial methyl group the corresponding shifts are 5.96,9.03 and 0.05 respectively. The shielding by an axial methyl group relative to an equatorial methyl group has been attributed to steric interactins.

Schneider and Hoppen ${ }^{6}$ have studied the $\alpha, \beta$ and $\gamma$ effects of various substituents $\mathrm{X}(\mathrm{X}=\mathrm{F}, \mathrm{Cl}, \mathrm{Br}, \mathrm{I}, \mathrm{OH}, \mathrm{OMe})$ in $35 \mathrm{a}$ and $35 \mathrm{~b}$. It has been found that the magnitude and even the sign of substituent effects can be changed by introducing additional alkyl groups in the $\alpha, \beta$ and $\gamma$ positions. The shifts induced on $\beta$ carbons are found to be independent of the nature of the substituent $\mathrm{X}$.

The ${ }^{13} \mathrm{C}$ NMR data of 4 - hydroxypiperidines [36] have been analysed ${ }^{7}$ and compared with those of analogous piperidines. The results indicate that substituent effects are markedly influenced by steric interaction.

A method of assigning the configuration of a substituent in saturated six-membered ring compounds, existing in chair conformation, from ${ }^{13} \mathrm{C}$ chemical shift of a single epimer has been suggested by Pandiarajan and Manimekalai.

\section{4. ${ }^{13} \mathrm{C}-{ }^{-1} \mathrm{H}$ Coupling Constants}

The ${ }^{13} \mathrm{C}^{-1} \mathrm{H}$-coupling constants are useful parameters in the study of organic molecules.

One bond coupling constant ${ }^{1} \mathrm{~J}_{\mathrm{CH}}$ is given by equation 9 , where $\%$ s represents the percentage ' $s$ ' character of the carbon hybrid orbital participating in the $\mathrm{C}-\mathrm{H}$ bond.

$$
{ }^{1} \mathrm{~J}_{\mathrm{CH}}=5 \mathrm{X}[\% \mathrm{~s}][\mathrm{Hz}]
$$

Table 2. Two-bond coupling constants, ${ }^{2} \mathrm{~J}_{\mathrm{CH}}$

\begin{tabular}{ll}
\hline Compound & ${ }^{1} \mathrm{~J}_{\mathrm{CH}[\mathrm{Hz}]}$ \\
\hline Ethane & -4.5 \\
Ethene & -2.4 \\
Ethyne & 49.3 \\
Benzene & 1.0 \\
Ethanol & 26.7 \\
\hline
\end{tabular}

Eq. 9 was later modified 79 as equation (10)

$$
{ }^{1} \mathrm{~J}_{\mathrm{CH}}=5.7 \mathrm{X}[\% \mathrm{~s}]-18.4[\mathrm{~Hz}]
$$

The ${ }^{1} \mathrm{~J}_{\mathrm{CH}}$ coupling constants in some compounds are given in Table 3 One - bond coupling constants, ${ }^{1} \mathrm{~J}_{\mathrm{CH}}$.

${ }^{2} \mathrm{~J}_{\mathrm{CH}}$ coupling constants are usually small. The ${ }^{2} \mathrm{~J}_{\mathrm{CH}}$ coupling constants of some compounds are given in Table 2 .

${ }^{3} \mathrm{~J}_{\mathrm{CH}}$-coupling constants depend on the dihedral angle. The coupling constant and dihedral angle are related by Karplus Conroy relation (eqution 11)

$$
{ }^{3} \mathrm{~J}_{\mathrm{CH}}=4.26-\cos \varphi+3.56 \cos 2 \varphi
$$

${ }^{3} \mathrm{~J}_{\mathrm{CH}}$-coupling constants of some compounds are given Table 3.

${ }^{13} \mathrm{C}-{ }^{13} \mathrm{C}$ coupling is usually not observed, except in compounds that have been deliberately enriched with ${ }^{13} \mathrm{C}$, because of the low probability of two adjacent ${ }^{13} \mathrm{C}$ atoms in a molecule.

${ }^{1} \mathrm{~J}_{\mathrm{cc}}$ depends on the hybridisation of the two carbon atoms involved. In terms of the ' $s$ ' character of the two bonding hybrid orbitals, ${ }^{1} \mathrm{Jcc}_{\mathrm{cc}}$ may be given by equation 12 .

$$
{ }^{1} \mathrm{~J}_{\mathrm{cx}} \mathrm{J}_{\mathrm{cy}}=7.3[\% \mathrm{sx}][\% \mathrm{sy}] / 100-17 \mathrm{~Hz}
$$

${ }^{1} \mathrm{~J}_{\mathrm{cc}}$ coupling constants of some compounds are given Table 4.

The ${ }^{2} \mathrm{~J}_{c c}$ and ${ }^{3} \mathrm{~J}_{\mathrm{cc}}$ coupling constants of some compounds are given in Table 5 .

The values of ${ }^{1} \mathrm{~J}_{\mathrm{CH}},{ }^{2} \mathrm{~J}_{\mathrm{CH}},{ }^{3} \mathrm{~J}_{\mathrm{CH}},{ }^{1} \mathrm{~J}_{\mathrm{CC}},{ }^{2} \mathrm{~J}_{\mathrm{CC}},{ }^{3} \mathrm{~J}_{\mathrm{CC}}$ in various aliphatic, alicyclic, aromatic and heterocyclic compounds have been reported.

\section{Two - dimensional NMR Spectroscopy}

In one-dimensional NMR spectrum, the abscissa corresponds to the frequency axis and ordinate gives the intensities of the signals. In a two dimensional 
NMR spectrum, both the abscissa and the ordinate are frequency axes, with the intensities constituting a third.

The two-dimensional methods are based on the couplingbetween nuclei. The mostimportant two-dimensional NMR spectra are those of the type which show either ${ }^{1} \mathrm{H}$ vs ${ }^{1} \mathrm{H}$ or ${ }^{1} \mathrm{H}$ vs ${ }^{13} \mathrm{C}$ chemical shift correlations.

Some of the important types of 2-D experiments are given below.

\subsection{Homonuclear Correlation Spectroscopy (HOMOCOSY)}

In this type of spectrum, ${ }^{1} \mathrm{H}$ Chemical shifts along both frequency axes are correlated with each other. The ${ }^{1} \mathrm{H}$ spectrum appears along the diagonal as contours responding peak intensities. The off-diagonal contours are the cross peaks. A horizontal line drawn from a cross peak will intercept a contour on the diagonal and a vertical line from the same cross peak will intercept another contour on the diagonal with which the first diagonal contour is coupled. Thus, we can assign signals unambiguously.

The basic COSY gives the same information, obtained through the classical ${ }^{1} \mathrm{H}-{ }^{1} \mathrm{H}$ decoupling procedure. In general, strongly coupled protons are better handled ina COSY experiment than with conventional ${ }^{1} \mathrm{H}-{ }^{1} \mathrm{H}$ decoupling.

The basic COSY, however, often results in considerable overlap along the diagonal. Thus, it is difficult to make assignments. This can be alleviated by a Double Quantum Filtered COSY (DQFCOSY).

For example, in the basic COSY spectrum of geraniol [37] (Figure 3), the signals for the three methyl groups are severely overlapped, as are those for the two methyl groups. However, in the DQFCOSY spectrum (Figure 4) H-8 and H-9 methyl proton signals are cleanly separated,

Table 3. Three-bond coupling constants, ${ }^{3} \mathrm{~J}_{\mathrm{CH}}$

\begin{tabular}{cc}
\hline Compound & ${ }^{3} \mathrm{~J}_{\mathrm{CH}}(\mathrm{Hz})$ \\
\hline Pyridine & $\mathrm{C}-2-\mathrm{H}-4=6.9$ \\
& $\mathrm{C}-4-\mathrm{H}-2=6.3$ \\
\multirow{5}{*}{ Furan } & $\mathrm{C}-3-\mathrm{H}-5=6.6$ \\
& $\mathrm{C}-2-\mathrm{H}-6=11.2$ \\
& $\mathrm{C}-2-\mathrm{H}-4=7.0$ \\
& $\mathrm{C}-2-\mathrm{H}-5=6.9$ \\
& $\mathrm{C}-3-\mathrm{H}-5=6.0$ \\
\hline
\end{tabular}

and the small allylic coupling to H-6 is apparent through the off - diagonal cross peak. The COSY lacks the H-1, $\mathrm{H}-4$ and the $\mathrm{H}-2, \mathrm{H}-4$ couplings that are present in the DQFCOSY.

\subsection{Heteronuclear Correlation Spectroscopy (HETCOR)}

The HETCOR spectrum correlates the peaks of ${ }^{1} \mathrm{H}$ spectrum with the peaks of ${ }^{13} \mathrm{C}$ spectrum, and shows the specific protons attached to each carbon. The ${ }^{1} \mathrm{H}$ spectrum is presented on the vertical axis and the ${ }^{13} \mathrm{C}$ spectrum on the horizontal axis. The ${ }^{1} \mathrm{H}-{ }^{13} \mathrm{C}$ correlation is shown by the off - diagonal contours.

In a HETCOR spectrum, ${ }^{13} \mathrm{C}$ nuclei have much wider chemical shift ranges than protons, and are a collection of singlets, due to the absence of homonuclear coupling. Thus, the information about proton frequencies can be gained from the dispersed ${ }^{13} \mathrm{C}$ signals more accurately.

Evans et al. ${ }^{8}$ have used the HETCOR spectrum to assign the carbon signals of 38 , a natural product extracted from beans. Structural elucidation has been made for complicated molecules like 39 and 40.

\subsection{Nuclear Overhauser and Exchange Spectroscopy (NOESY)}

Nuclear Overhauser and Exchange Spectroscopy assemble all the ${ }^{1} \mathrm{H}-{ }^{1} \mathrm{H}$ spectrum effects in a molecule into a single spectrum. In a NOESY spectrum, the ${ }^{1} \mathrm{H}$ spectrum is represented by contours along the diagonal,

Table 4. One-bond

\begin{tabular}{cc}
\multicolumn{2}{c}{ coupling constants, ${ }^{1} \mathrm{~J}_{\mathrm{cc}}$} \\
\cline { 1 - 2 } Compund & ${ }^{1} \mathrm{~J}_{\mathrm{cc}(\mathrm{Hz})}$ \\
\hline Ehane & 34.6 \\
Benzene & 57.0 \\
Furan & 69.1 \\
Ethanol & 37.7 \\
\hline
\end{tabular}

Table 5. Two-bond and Three-bond coupling constants, ${ }^{2} \mathrm{~J}_{\mathrm{cc}}$ and ${ }^{3} \mathrm{~J}_{\mathrm{cc}}$

\begin{tabular}{lcc}
\hline \multicolumn{1}{c}{ Compound } & ${ }^{2} \mathrm{~J}_{c c}(\mathrm{~Hz})$ & ${ }^{3} \mathrm{~J}_{c c}(\mathrm{~Hz})$ \\
\hline Propyne & 11.8 & - \\
Cyclobutanone & 9.5 & - \\
Pyridine & - & 13.95 \\
Aniline & - & 7.9 \\
\hline
\end{tabular}


and the off diagonal contours represent non-bonding ${ }^{1} \mathrm{H}-{ }^{1} \mathrm{H}$ interactions with protons that are nearby in space.

Many attempts have been made to improve the practical techniques in 2 - D NMR and to make structural elucidation and conformational assignment of complicated molecules.

\section{Scope of the Present Investigation}

In the present study, DAERM method and Altona's equation are used to calculate torsional angles from the reported proton - proton vicinal coupling constants of the following compounds:

$r(2), c(6)$ - diphenoxan -4- one

$\mathrm{t}(3)$-Methyl -r(2),c(6) - diphenylpiperidin-4- one

$\mathrm{t}(3)$-Ethyl -r(2),c(6) - diphenylpiperidin-4- one

$\mathrm{t}$ (3)-isopropyl -r(2),c(6) - diphenylpiperidin-4- one (44)

3, 3 -dimethy -r(2),c(6) - diphenylpiperidin-4- one

N-Methyl-t(3)-Methyl -r(2),c(6) -

diphenylpiperidin-4- one

N-Methyl-t(3)-isopropyl -r(2),c(6) -

diphenylpiperidin-4- one

N-Methyl-3,3-dimethyl -r(2),c(6) diphenylpiperidin-4- one

$\mathrm{C}(4)$-Hydroxy -r(2),c(6) - diphenylpiperidine

$\mathrm{C}(4)$-Hydroxy - t(3)-methyl - r(2),c(6) -

diphenylpiperidine

$\mathrm{C}(4)$-Hydroxy - t(3)-ethyl - r(2),c(6) -

diphenylpiperidine

C(4) -Hydroxy - 3,3- dimethyl - r(2),c(6) -

diphenylpiperidine

A method is proposed to find whether the vicinal coupling in a - $\mathrm{CHX}$ - $\mathrm{CH} 2$ - system represents a single conformation or an equilibrium between two or more conformations. This method is applied in conformational analysis of the following compounds:

N-Phenylcarbamoyl-r(2),c(6)-diphenylpiperidin4-one
N-Phenylcarbamoyl-t(3)-methyl-r(2),c(6)-

diphenylpiperidin-4-one

N-Phenylcarbamoyl-t(3)-ethyl-r(2),c(6)-

diphenylpiperidin-4-one

N-Phenylcarbamoyl-t(3)-isopropyl-r(2),c(6)-

diphenylpiperidin-4-one

N-Phenylcarbamoyl-t(3),t(5)-dimethyl-r(2),c(6)-

diphenylpiperidin-4-one

N-Nitroso-r(2),c(6)-diphenylpiperidin-4-one

N-Nitroso-t(3) - methyl -r(2),c(6) - diphenylpiperi-

din-4- one

N-Nitroso-t(3),t(5)- dimethyl -r(2),c(6) -

diphenylpiperidin-4- one

NOSEY spectra have been recorded for 59 and 60.

${ }^{1} \mathrm{H}$ NMR spectra have been recorded for $\mathrm{t}(3)$-methyl -r(2),c(7) - diphenylhomopiperazin-5- one (61), t (3)-ethyl $-r(2), c(7)$ - diphenyl homopiperazin-5- one (62) and $t$ (3)-isopropyl -r(2),c(7) - diphenyl homopiperazin-5one (63) have been recorded at $500 \mathrm{MHz}$ in DMSO- $\mathrm{d}_{6}$. The various chemical shifts and coupling constants have been extracted. These values are compared with those in $\mathrm{CDCl}_{3}$. The solvent effect is discussed.

${ }^{1} \mathrm{H}$ NMR spectra of $61 \& 62$ have been recorder at two different concentrations. The effect of concentration is discussed.

${ }^{1} \mathrm{H}$ NMR spectra have been recorded for compound 62 at $300 \mathrm{~K}$ and $333 \mathrm{~K}$. The temperature effect is discussed. ${ }^{1} \mathrm{H}$ NMR spectra have been recorded for compound 63 at $300 \mathrm{~K}$ and $333 \mathrm{~K}$. The temperature effect is discussed.

${ }^{13} \mathrm{C}$ NMR spectra have been recorded for compound 61-63 IN DMSO - $d_{6}$. The chemical shifts are compared with those in $\mathrm{CDCl}_{3}$. The solvent effect is discussed.

COSY, NOESY and ${ }^{13} \mathrm{C}-{ }^{1} \mathrm{H}$ correlation spectra have been recorded for compounds 61-63. These are used to assign the signals unambiguously.

\section{Result and Dicussion}

\subsection{Calculation of Torsional Angle from Vicinal Coupling Constants}

r[2], c[6] - Diphenyl - 1 - heteracyclohexan - 4 - ones have shown to exist largely in a single conformation in solution.52, 1004 - hydroxyl - r[2], c[6]- diphenylpiperidines have been shown to exist largely in single chair 
conformation in solution. 76 Vicinal coupling constants have been reported for these compounds. However, no attempt has been made to determine the proton - proton torsional angles from the vicinal coupling constants in these compounds. In the present study, the proton proton torsional angles are calculated from the vicinal coupling constants of 41-52, using DAERM method and Altona's equation. r[2],c[6]- Diphenyloxan - 4 - one [41].

This compound has been shown to exist largely in single chair conformation with equatorial orientation of phenyl groups. The reported vicinal coupling constants $J_{\text {aа }}$ and $\mathrm{J}_{\mathrm{ae}}$ are 11.70 and $2.56 \mathrm{~Hz}$ respectively. ${ }^{9}$

\subsection{Calculation of Torsional Angles from Vicinal Coupling Constants - using Altona's}

\section{Equation}

For a tri-substituted system, Altona's equation is given by

$$
\begin{aligned}
\mathrm{J}_{\mathrm{HH}}= & 13.22 \cos ^{2} \varphi-0.99 \cos \varphi+\Delta \mathrm{x}\left[0.87-2.46 \cos ^{2}\right. \\
& (19.91 \Delta \mathrm{xl} \pm \zeta \varphi)]
\end{aligned}
$$

where, $\Delta \mathrm{x}$ is the difference between the electronegativities of a substituent attached to the $\mathrm{C}-\mathrm{C}$ segment and hydrogen

$\varphi$ is the torsional angle between the two hydrogen, and $\zeta$ is constant having a value of \pm according to the orientation of the substituent.

A substituent is said to be positive if the projected valency angle between the substituent and the hydro- gen attached to the carbon bearing the substituent is about $120^{\circ}$, when measured in the direction in which $\varphi$ is measured. If this angle is about $240^{\circ}$, the substituent is said to be negative. For a positive substituent, $\zeta$ is taken as +1 , and for a negative substituent is taken as - 1 .

Using Haasnoot method, it is possible to calculate $\varphi_{5 \mathrm{e}, 6 \mathrm{a}}$. The three substituents in C-5 - C-6 bond are CO, $\mathrm{Ph}$, and $\mathrm{O}$. The electronegativity of oxygen was taken as 3.50 [Allred - Rochow electronegativity] ${ }^{101}$. The electronegativity of the phenyl group was taken as 2.58 . The elctronegativity of the $\mathrm{CO}$ group was calculated as 2.92 , following the method of Bratsch ${ }^{10}$. The orientation of the substituents show that $\mathrm{Ph}$ and $\mathrm{CO}$ groups are positive and $\mathrm{O}$ is negative (Figure 6).

When the parameters and the electronegativity differences are substituted in Eq 8, we get,

$$
\begin{aligned}
\mathrm{J}_{\mathrm{ae}}= & 13.22 \cos ^{2} \varphi-0.99 \cos \varphi+0.38\left[0.87-2.46 \cos ^{2}(19.9\right. \\
& \mathrm{x} 0.38+\varphi)]+0.72\left[0.87-2.46 \cos ^{2}(19.9 \times 0.72+\right. \\
& \varphi)]+0.87\left[0.87-2.46 \cos ^{2}(19.9 \times 0.87+\varphi)\right]
\end{aligned}
$$

Spectral value for $\mathrm{J}_{\mathrm{ae}}=2.56 \mathrm{~Hz}$

$\varphi_{\mathrm{ae}}$ comes as $58.9^{\circ}$

The torsional angles have been calculated for the other Compounds, using similar procedure. The values are listed in Table 6.

For 2, 6 - Diphenyloxan - 4 - one, both the methods give almost the same values of torsional angle. For the other compounds, the torsional angles calculated by Altona's equation are $2-4^{0}$ higher than those calculated using DAERM method.

Table 6.

\begin{tabular}{ccccccccc}
\hline Com pound & \multirow{2}{*}{$\mathrm{J}_{\mathrm{ae}}$} & $\mathrm{J}_{\text {aa }}$ & \multicolumn{3}{c}{ DAERM Method } & \multicolumn{3}{c}{ Altona's method } \\
\cline { 4 - 9 } & & & $\varphi_{\mathrm{ae}}$ & $\varphi_{\mathrm{aa}}$ & $\mathrm{k}_{1}$ & $\mathrm{~K}_{2}$ & $\varphi_{\mathrm{ae}}$ & $\varphi_{\text {aa }}$ \\
\hline 41 & 2.56 & 11.70 & 59.0 & 179.0 & 10.78 & 11.98 & 58.9 & 178.9 \\
42 & 2.83 & 11.84 & 57.8 & 177.8 & 11.02 & 12.24 & 62.3 & 182.3 \\
43 & 2.90 & 11.70 & 57.1 & 177.1 & 10.85 & 12.05 & 61.7 & 181.7 \\
44 & 3.00 & 11.70 & 56.5 & 176.5 & 10.83 & 12.04 & 60.8 & 180.3 \\
45 & 3.12 & 12.02 & 56.3 & 176.3 & 11.11 & 12.34 & 59.8 & 179.8 \\
46 & 3.18 & 12.19 & 56.3 & 176.3 & 11.30 & 12.56 & 59.4 & 179.4 \\
47 & 3.60 & 11.70 & 53.4 & 173.4 & 10.97 & 12.91 & 56.0 & 176.0 \\
48 & 3.56 & 12.50 & 54.8 & 174.8 & 11.62 & 12.91 & 56.3 & 176.3 \\
49 & 1.94 & 11.42 & 62.6 & 182.6 & 10.58 & 11.95 & 67.1 & 187.1 \\
50 & 2.31 & 11.33 & 60.6 & 180.0 & 10.44 & 11.60 & 63.6 & 183.6 \\
51 & 2.16 & 11.35 & 61.0 & 181.0 & 10.47 & 11.63 & 65.0 & 185.0 \\
52 & 2.86 & 11.51 & 57.0 & 177.0 & 10.65 & 11.84 & 59.1 & 179.1 \\
\hline
\end{tabular}


For compounds 41, 42 and 49, the AMI calculations have given torsional angles as 55.0, 54 and 56.3 respectively. These values are close to those calculated by DAERM method.

\section{References}

1. Thomas WA. Annu Rev NMR (Nuclear Magnetic Resonance) Spectroscopy. 1968; 1(43).

2. Bladon P. Annu NMR (Nuclear Magnetic Resonance) Spectroscopy. 1969; 2(1).

3. Thomas WA. Annu Rev NMR (Nuclear Magnetic Resonance) Spectroscopy. 1970; 3(91).
4. Anet FAL, Anet R. In: Nachod FC, Zuckerman JJ, editors. Determination of organic structure from physical methods. New York: Academic Press; 1971.

5. Anet FAL, Anet R. In: Jackman LM, Cotton FA, editors. Dynamic nuclear magnetic resonance spectroscopy. New York: Academic Press; 1975.

6. Lukas G. Bull Soc Chem (France). 351(172).

7. Tanable M. Biosynthesis In: Geissman TA, editor. Specialist Periodical Reports. London: The Chemical Society; 1973.

8. Lambert JB, Featherman SI. Chem Rev. 1975; 75:611.

9. Levy GC, Nelson GL. Carbon - 13 Nuclear magnetic resonance for organic chemists. New York: Wiley-Interscience; 1972.

10. Hore PJ. J Magn Reson. 1985; 62:561. 